\title{
Intra- and interobserver agreement in the diagnosis of malocclusion in sleep-disordered breathing
}

\author{
Concordância intra e inter observadores no diagnóstico da má oclusão dentária nos \\ distúrbios respiratórios do sono \\ Fernando Rodrigues Carvalho', Débora Aparecida Lentini-Oliveira², Graziele Maria Missiano Carvalho³, Julio \\ Motta Singer ${ }^{4}$, Lucila Bizari Fernandes Prado 5 , Gilmar Fernandes Prado 6 , Luciane Bizari Coin Carvalho ${ }^{7}$
}

\begin{abstract}
Sleep-disordered breathing (SDB) is often related to malocclusion, and dentists should be able to recognize occlusal changes that may be associated with the development, onset, or persistence of SDB. Although clinical examination is routinely used by specialists in orthodontics and functional jaw orthopedics, differences in diagnosis are very common. Method: Two observers, both dentists specializing in functional jaw orthopedics, examined 56 children aged 7 to 9 years. Intra- and interobserver agreement in identification of functional orthopedic and orthodontic conditions were assessed. Results: Intraobserver agreement was strong for all variables. Interobserver agreement was also strong, except for the variable overbite, which showed good agreement. Conclusion: Diagnostic criteria provide an opportunity for dentists to recognize dental malocclusions that may be associated with sleep-disordered breathing.
\end{abstract}

Keywords: malocclusion, obstructive sleep apnea, child.

\section{RESUMO}

Os distúrbios respiratórios do sono podem estar relacionados com problemas de má oclusão. O cirurgião dentista deve estar apto a reconhecer as alterações oclusais que possam estar associados com o desenvolvimento, instalação ou manutenção dos distúrbios respiratórios do sono. Apesar do exame clínico ser rotineiramente utilizado pelos especialistas em ortodontia e ortopedia funcional dos maxilares, a divergência no diagnóstico é muito frequente. Método: Dois observadores, cirurgiões dentistas, ortopedistas funcionais dos maxilares, examinaram 56 crianças entre 7 e 9 anos de idade para verificar a concordância intra e inter observador na identificação de problemas ortodônticos e ortopédicos funcionais. Resultados: A concordância intraobservador foi forte em todas as variáveis pesquisadas. A concordância interobservador também foi forte exceto na variável sobremordida que foi apresentou boa concordância. Conclusão: 0 estabelecimento de critérios diagnósticos explícitos dá oportunidade ao cirurgião dentista de reconhecimento das más oclusões dentárias potencialmente associadas aos distúrbios respiratórios do sono.

Palavras-chave: má oclusão, apneia do sono tipo obstrutiva, criança.

Malocclusion is associated with many problems, ranging from respiratory conditions to impaired masticatory performance ${ }^{1-5}$ and aesthetic concerns, all of which have a major impact on quality of life ${ }^{6-8}$. As sleep-disordered breathing (SDB) is related to malocclusion ${ }^{9,10}$, dentists should be able to recognize the signs of occlusal changes that may be associated with the development ${ }^{9,11}$, onset, and persistence of SBD ${ }^{9,10,12}$. The trained dental practitioner can contribute to the diagnosis and treatment plan for $\mathrm{SDB}^{9,13}$ and to early identification of risk factors, contributing to the prevention of problems that

${ }^{1}$ D.D.S., PhD, Specialist in orthodontics, Departamento de Medicina, Universidade Federal de São Paulo; Sao Paulo SP, Brazil;

${ }^{2}$ D.D.S., PhD, Specialist in pediatric dentistry, Departamento de Medicina, Universidade Federal de São Paulo; Sao Paulo SP, Brazil;

${ }^{3}$ D.D.S., Specialist in Implantology;

${ }^{4}$ Departamento de Estatística, Instituto de Matemática e Estatística, Universidade de São Paulo; Sao Paulo SP, Brazil;

${ }^{5} \mathrm{MD}$, PhD, Neuro-Sono, Departamento de Neurologia, Universidade Federal de São Paulo; Sao Paulo SP, Brazil;

${ }^{6} \mathrm{MD}$, PhD, Neuro-Sono, Departamento de Neurologia, Universidade Federal de São Paulo; Sao Paulo SP, Brazil;

${ }^{7}$ PhD, Neuro-Sono, Departamento de Neurologia, Universidade Federal de São Paulo. Sao Paulo SP, Brazil;

Correspondence: Luciane BC Carvalho. Rua Claudio Rossi, 394; 01547-000 São Paulo SP, Brasil. E-mail: neuro.sono.unifesp@gmail.com

Support: Fundação de Amparo à Pesquisa do Estado de São Paulo (no. 2010/02633-2).

Conflict of interest: There is no conflict of interest to declare.

Received 13 May 2013; Received in final form 19 September 2013; Accepted 26 September 2013. 
begin in childhood and can persist into adulthood ${ }^{14}$. SDB is associated with permanent physical, psychological, and neurological damage ${ }^{15}$. Early recognition and treatment can reduce its high economic burden and improve quality of life $\mathrm{e}^{14}$.

Malocclusion is evaluated along the sagittal, vertical, and transverse planes, and classified as compared with normal occlusion on the basis of clinical examination. The dentist can then establish an orthodontic diagnosis and plan treatment with appliances to correct any deviations.

Although clinical examination is routinely used by specialists in orthodontics and functional jaw orthopedics, differences in diagnosis are very common ${ }^{16}$; therefore, the definition of clear diagnostic criteria is paramount. Within this context, and in view of the importance of reproducibility and applicability in the diagnosis of SBD, a highly prevalent disease, we conducted this study to evaluate intra- and interobserver agreement in malocclusion diagnosis.

\section{METHOD}

Two observers, both dentists specializing in functional jaw orthopedics and having extensive experience in the classification of malocclusion, examined 56 children (aged 7 to 9 years) recruited from public elementary schools in the municipality of Osasco, state of São Paulo, Brazil (Table 1).

We included children aged 7 to 9 years whose parents had signed a consent form for participation in the study. We excluded children who were receiving or had previously received orthodontic or functional jaw orthopedics treatment, those with a history of cleft lip and/or palate, and those with neurological syndromes. Children whose first permanent molars had not yet erupted were excluded from evaluation of Angle's classification. This study was approved by the Universidade Federal São Paulo/Hospital São Paulo Research Ethics Committee under protocol no.1181/09.

\section{Procedure}

The first observer examined children twice with an interval of 7 days between observations. The second observer examined the children once, on the same day that the first examiner observed the children for the second time.

Assessment of occlusion was divided into sagittal, verti$\mathrm{cal}$, and transverse analysis.

Table 1. Characteristics of the sample.

\begin{tabular}{cccc}
\hline & Boys & Girls & Total \\
\hline 7 years & 1 & 7 & 8 \\
8 years & 7 & 10 & 17 \\
9 years & 17 & 14 & 31 \\
\hline Total & 25 & 31 & 56 \\
\hline
\end{tabular}

Sagittal assessment: performed according to Angle's classification ${ }^{19}$, which is based on the anteroposterior relationship of the mandible and maxilla and anteroposterior relationships between the first permanent molars. It is divided into three classes:

1. Class I: is characterized by a normal relationship between the mandible and the maxilla and the correct relationship between the mesiodistal permanent molars, i.e., the mesiobuccal cusp of the permanent maxillary first molar occludes in the vestibular groove of the permanent mandibular first molar.

2. Class II: is characterized by distal displacement of the mandibular first molars in relation to their maxillary counterparts, such that the mesiobuccal cusp of the maxillary first molar occludes with the distal aspect of the second premolar. The entire lower arch is positioned distally to the upper arch; hence, the maxillary incisors are mesial to their mandibular counterparts.

3. Class III: is characterized by mesial displacement of the permanent first molars; the entire lower arch is situated mesially in relation to the upper arch.

Overjet is the extent to which the maxillary incisors protrude beyond the mandibular incisors on the horizontal plane. It was considered normal if the vestibular surface of the mandibular incisors contacted the palatal surface of maxillary incisors or if the distance between these surfaces was $<2 \mathrm{~mm}$.

Vertical assessment: was based on measurement of overbite, i.e. the extent of overlap of the maxillary teeth over the mandibular teeth in the vertical plane. It was considered normal when this overlap ranged from 0 to $+4 \mathrm{~mm}$. If the maxillary incisors overlapped the mandibular incisors by more than $4 \mathrm{~mm}$, or if the teeth touched the palate, this was considered excessive overbite. Conversely, open bite was diagnosed when there was no contact between the maxillary and mandibular incisors, i.e., negative overbite.

Transverse assessment: we checked for crossbite, which is defined as an abnormal labiolingual relationship or buccolingual relationship between the maxillary and mandibular teeth. Bite reversal occurs where the mandibular teeth overlap with the maxillary teeth. It is the result of a large discrepancy between the maxilla and the mandible. Dental crowding was characterized by lack of space in the dental arch, causing displacement and misalignment of teeth.

The observers then completed a form with the following data: Angle classification (Class I, II or III), overjet (present or absent), overbite (present or absent), anterior open bite (present or absent), crossbite (present or absent), and crowding (present or absent).

\section{Statistical analysis}

Cohen's kappa coefficient was used to assess intra- and interobserver agreement for the diagnosis of orthodontic and functional orthopedic conditions of the jaws. Cohen 
kappa ${ }^{17}$ is an index used on a nominal scale to assess the extent to which observations deviate from the expected due to chance, thus providing an indicator of the reliability of this information. Interpretation of this coefficient was based on the cutoff values listed in Table $2^{18}$.

\section{RESULTS}

Only 53 of the 56 children included underwent assessment of Angle classification, because three children had no erupted

Table 2. Interpretation of the level of agreement ${ }^{18}$

\begin{tabular}{lc}
\hline Kappa coefficient $(\mathrm{K})$ & Level of agreement \\
\hline$<0.20$ & None \\
$0.21-0.40$ & Weak \\
$0.41-0.60$ & Moderate \\
$0.61-0.80$ & Good \\
$0.81-1.0$ & Strong \\
\hline
\end{tabular}

permanent first molars. For the other malocclusions, all 56 children were examined. The number of participants for each type of occlusion according to the two observations of observer 1 and the one observation of observer 2 is shown in Table 3.

Intraobserver agreement was strong $(>0.8)$ for all parameters analyzed (type of occlusion according to the Angle classification, overjet, overbite, open bite, crowding, and crossbite, Table 4). Interobserver agreement was good for overbite and strong for all other parameters (Table 5).

\section{DISCUSSION}

The main finding of this study was the high intraobserver and interobserver agreement for the diagnosis of malocclusions, which may be attributed to the explicitly defined diagnostic criteria currently adopted and to the familiarity of the observers with the classification of malocclusion.

Table 3. Number of participants according to the occlusion*.

\begin{tabular}{|c|c|c|c|c|}
\hline & & & Observer 2 & Total observed \\
\hline & Observation 1 & Observation 2 & & \\
\hline Angle's classification & & & & 53 \\
\hline Classe I & 36 & 34 & 35 & \\
\hline Classe II & 16 & 17 & 17 & \\
\hline Classe III & 1 & 2 & 1 & \\
\hline Oveverjet & & & & 56 \\
\hline Present & 8 & 9 & 10 & \\
\hline Absent & 48 & 47 & 46 & \\
\hline Overbite & & & & 56 \\
\hline Present & 20 & 35 & 19 & \\
\hline Absent & 36 & 21 & 37 & \\
\hline Open bite & & & & 56 \\
\hline Present & 2 & 2 & 2 & \\
\hline Absent & 54 & 54 & 54 & \\
\hline Cross bite & & & & 56 \\
\hline Present & 21 & 20 & 22 & \\
\hline Absent & 35 & 36 & 34 & \\
\hline Crowding & & & & 56 \\
\hline Present & 23 & 23 & 25 & \\
\hline Absent & 33 & 33 & 31 & \\
\hline
\end{tabular}

*The two observations of observer 1 and the one observation of observer 2 .

Table 4. Concordance intraobserver for all malocclusions evaluated.

\begin{tabular}{lcccc} 
& Intraobserver kappa coefficient & 95\% confidence interval & $p$-value & Interpretation of kappa coefficient \\
\hline Angle classification & 0.838 & $0.592-1.000$ & $p<0.001$ & strong \\
Overjet & 0.931 & $0.669-1.000$ & $p<0.001$ & strong \\
Overbite & 0.808 & $0.546-1.000$ & $p<0.001$ & strong \\
Open bite & 1.0 & & $p<0.001$ & strong \\
Cross bite & 0.885 & $0.623-1.000$ & $p<0.001$ & strong \\
Crowding & 0.926 & $0.664-1.000$ & $p<0.001$ & strong \\
\hline
\end{tabular}


Table 5. Interobserver agreement for all malocclusions evaluated.

\begin{tabular}{lcccc} 
& Intraobserver kappa coefficient & 95\% confidence interval & $p$-value & Interpretation of kappa coefficient \\
\hline Angle classification & 0.84 & $0.595-1.000$ & $p<0.001$ & strong \\
Overjet & 0.868 & $0.608-1.000$ & $p<0.001$ & strong \\
Overbite & 0.767 & $0.506-1.000$ & $p<0.001$ & good \\
Open bite & 1.0 & & & strong \\
Cross bite & 0.848 & $0.587-1.000$ & $p<0.001$ & strong \\
Crowding & 0.854 & $0.593-1.000$ & $p<0.001$ & strong \\
\hline
\end{tabular}

In this study the two observers were specialized dentists that have extensive experience in this area, but as the examination of malocclusions is also part of the academic dental curriculum, dentists who are not experts should also be able to diagnose these issues reliably, although we emphasize that it is essential to define the diagnostic criteria clearly in advance of examination.

Diagnosis is very important, because it is the main determinant of treatment decisions. In orthodontics and functional jaw orthopedics, clinical examination of occlusal status is an essential practice. The classification of patients according to malocclusion facilitates communication among professionals and choice of treatment protocols.

In this study, two observers assessed the main characteristics of malocclusions known to be associated with $\mathrm{SDB}^{1,10,20,21}$. We found that the degree of agreement between the observers for diagnosis of these malocclusions was high (Figure 1). Conversely, Luke et al. reported poor agreement among 39 professionals for diagnosis and treatment planning in a sample of six patients. Their poor performance was attributed to the need for better-defined diagnostic criteria ${ }^{16}$.

Future studies are needed to check which malocclusions are more closely associated with SDB, because although all the above-mentioned malocclusions are reported to be associacted with SDB, it is possible that there is

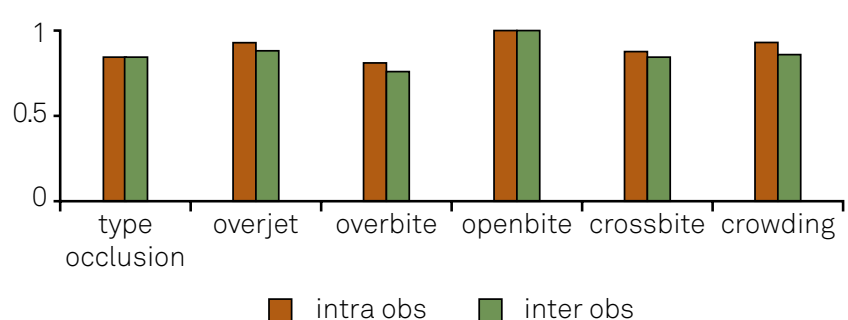

Figure. Comparison between intra- and inter observer agreement for all malocclusions evaluated.

a difference in the degree of association between SDB and each type of malocclusion.

It should be noted that although sample selection was not concerned with the distribution by gender and age of the participants, this would not have influenced achieving the main objective of this study: to verify the intra- and interobserver agreement.

In conclusion, both intra- and interobserver agreement were fully satisfactory for all of the evaluated parameters. We attribute this high level of agreement to the clear definition of the diagnostic criteria and to the familiarity of dental practitioners with the Angle classification. Clearly established diagnostic criteria can give dentists the opportunity to recognize dental malocclusions potentially associated with SDB.

\section{References}

1. Guilleminault C, Pelayo R, Leger C, Clerk A, Bocian RC. Recognition of sleep-disordered breathing in children. Pediatrics 1996;98:871-872.

2. Marklund M, Franklin KA, Sahlin C, Lundgren R. The effect of a mandibular advancement device on apneas and sleep in patients with obstructive sleep apnea. Chest 1998;113:707-713.

3. Shintani T, Asakura K, Kataura A. The effect of adenotonsillectomy in children with OSA. Int J of Pediatr Otorhinolaryngol 1998;44:51-58.

4. Guilleminault C, Lee JH, Chan A. Pediatric obstructive sleep apnea syndrome. Arch Pediatr Adolesc Med 2005;159:775-785.

5. Pirilä-Parkkinen K, Pirttiniemi P, Nieminen P, Tolonen U, Pelttari U, Löppönen $\mathrm{H}$. dental arch morphology in children with sleep disodered breathing. Eur J Orthod 2009;31:160-167.

6. O'Brien C, Benson PE, Marshman Z. Evaluation of a quality of life measure for children with malocclusion. J Orthod 2007;34:185-193.

7. Kalha AS. Evidence that of orthodontics improves long term psychological well being lacking. Evid Based Dent 2011;12:108-109.
8.

Arrow P, Brennan D, Spencer AJ. Quality of life and psychosocial outcomes after fixed orthodontic treatment: a 17-year observational cohort study. Community Dent Oral Epidemiol 2011;39:505-514.

9. Guilleminault C, Quo SD. Sleep-disordered breathing. A view at the beginning of the new Millennium. Dent Clin North Am 2001;45:643-656.

10. Caprioglio A, Zucconi M, Calori G, Troiani V. Habitual snoring, OSA and craniofacial modification. Orthodontic clinical and diagnostic aspects in a case control study. Minerva Stomatol 1999;48:125-137.

11. Mohsenin N, Mostofi MT, Mohsenin V. The role of oral appliances in treating obstructive sleep apnea.J Am Dent Assoc 2003;134:442-449.

12. Barsh LI. Responsibilities of the dental profession in recognizing and treating sleep breathing disorders. Compend Contin Educ Dent 1996;17:490-494.

13. Paskow H, Paskow S. Dentistry's role in treating sleep apnea and snoring. N J Med 1991;88:815-817.

14. Nixon GM, Brouillette RT. Sleep. 8: Paediatric obstructive sleep apnoea. Thorax 2005;60:511-516. 
15. Brouillette RT, Fernbach SK, Hunt CE. Obstructive sleep apnea in infants and children.J Pediatr 1982;100:31-40.

16. Luke LS, Atchison KA, White SC. Consistency of patient classification in orthodontic diagnosis and treatment planning. Angle Orthod 1998;68: 513-520.

17. Cohen J. Acoefficient of agreement for nominal scales. Educ Psychol Measur 1960;20:37-46.

18. Altman DG. Practical statistics for medical research. London: Chapman \& Hall. 1991;611.
19. Moyers RE. Classificação e terminologia da má oclusão. In: Moyers RE (Ed). Ortodontia traduzido por Décio Rodrigues Martins. Rio de Janeiro:Guanabara Koogan. 1987:265-282

20. Defabjanis P. Impact of nasal airway obstruction on dentofacial development and sleep disturbances in children: preliminary notes. J Clin Pediatr Dent 2003;27:95-100.

21. Cozza P, Polimeni A, Ballanti F. A modified monobloc for the treatment of obstructive sleep apnoea in paediatric patients. Eur $J$ Orthod 2004;26:523-530. 